Matgorzata Chatupnik* and Gavin Brookes*

\title{
'You said, we did': a corpus-based analysis of marketising discourse in healthcare websites
}

https://doi.org/10.1515/text-2020-0038

Received April 1, 2020; accepted July 21, 2021; published online August 12, 2021

Abstract: In recent years, social and political commentators have criticised the ongoing marketisation of the UK's state-based healthcare system, the National Health Service (NHS). This paper examines the websites of 187 NHS's Clinical Commissioning Groups (CCGs), exploring how the CCGs represent themselves and their actions, and considering the extent to which these reflect and indeed enact this process of marketisation. Taking a corpus-based approach to Critical Discourse Studies, the analysis shows how the CCGs represent themselves as accountable, collaborative, patient-centred, responsive and self-determining organisations. It is thus argued that these websites function as forms of 'prestige advertising', reflecting the increasingly marketised nature of contemporary UK healthcare. Following the analysis, the potential motivations for these representations are considered, as are their possible implications for website users and the broader UK healthcare landscape.

Keywords: advertising; corpus linguistics; critical discourse studies; healthcare communication; marketisation; transitivity

\section{Introduction}

The UK National Health Service (NHS) is the oldest state-based healthcare system in the world. Political and social commentators have criticised the ongoing privatisation of the NHS, perceiving this to threaten the NHS's founding principle of equal care that is free to all at the point of use (Baker et al. 2019). Although the process of NHS privatisation has taken place over the last forty years or so, it was accelerated by the 2012 Health and Social Care Act. This Act entailed the most

*Corresponding authors: Matgorzata Chatupnik, School of English, University of Nottingham, Trent Building, University Park, NG7 2RD Nottingham, UK,

E-mail: malgorzata.chalupnik@nottingham.ac.uk; and Gavin Brookes, Linguistics and English Language, Lancaster University, Bailrigg, LA1 4YW Lancaster, UK, E-mail: g.brookes@lancaster.ac.uk

¿ Open Access. @ 2021 Matgorzata Chatupnik and Gavin Brookes, published by De Gruyter. (co)BY This work is licensed under the Creative Commons Attribution 4.0 International License. 
extensive reorganisation of healthcare services in England in the history of the NHS. This included abolishing Primary Care Trusts and Strategic Health Authorities and replacing these with 211 regional Clinical Commissioning Groups (CCGs) responsible for organising, or 'commissioning', NHS services in England by putting services out to tender. Those services are then fulfilled by private service providers who are paid using public funds previously assigned to Primary Care Trusts. Krachler and Greer (2015: 215) point out how, through the Health and Social Care Act, the UK Government 'sought both to marketise (i.e. increase price-based competition between providers) and privatise (i.e. increase provision carried out by non-government providers).' In light of these developments, the present study examines how CCGs represent themselves and their actions on their websites, with a view to understanding whether and how such self-representations reflect and indeed enact the process of marketisation.

The paper comprises six sections. Following this Introduction, we position the current study in relation to theory and research on discourses of marketisation. Then, in the Methodology, we outline how these discourses will be identified and examined in the context of healthcare websites, introducing our analytical approach - a corpus-based approach to Critical Discourse Studies - and discussing our data, which is a corpus of the text from the websites of 187 CCGs. The Findings section presents the results of our investigation, revealing the means through which the processes of marketisation are embedded in the CCGs websites. The Discussion section considers the broader motivations of the CCGs' marketising self-representations, before the Conclusions section summarises the broader implications of our findings and reviews the main strengths and limitations of our approach.

\section{Literature review}

Marketisation is defined by Fairclough (2000: 163) as 'the extension of market modes of operation to new areas of social life'. Marketisation blurs the boundaries between discourses traditionally associated with the market and public domains. In the context of the public sector, 'public and non-profit organisations eventually come to look and sound like businesses' (Mautner 2010: 25), leading to 'institutional homogeneity that mirrors private sector forms' (Ozga 1998: 144). In this sense, non-promotional, informative texts become increasingly colonised by promotional ones (Fairclough 1992), producing 'a curious mix of technocratic and promotional discourses', of deferential and familiar, blending together bureaucratic jargon with 'emotionally loaded lexis and multi-modality' (Mautner 2010: 68).

Evidence of increased use of bureaucratic jargon in marketised public services texts can be observed, for example, in the growing use of forms of address such as 
customer and client (Barnett 2000; Furedi 2011; Sarangi and Slembrouck 1996). Their increasing prevalence is significant as, according to Fairclough (2000: 164), 'once an institution begins to treat people it provides services for in a market way, as customers or clients to whom they are trying to sell "products", then they acquire some authority - the authority which comes from the power to choose, and to shop around'. Barnett (2000) argues that marketisation may result in people adopting a more detached attitude towards public services, with the relationship between individuals and public services organisations thus becoming more transactional or contractual (Furedi 2011). This process of transactionalisation is visible in the types of business jargon that can permeate public services texts and interactions. This includes, for example, the use of the language of 'deliverology', wherein public services are framed as 'service providers' who 'deliver' services that become reconfigured into commodities (Morrish and Sauntson 2013). In healthcare contexts, this means patients become (re)framed as 'consumers' of services, and, being so, 'consume' these services as a matter of individual choice. Consequently, patients can become responsibilised for the health-related decisions they make (Arribas-Ayllon et al. 2011).

Concurrent with the increased use of bureaucratic jargon in marketised texts is the emphatic use of familiar language (Sarangi and Slembrouck 1996). This is another example of commercial language 'bleeding into' public services, with the 'public colloquialism' of advertising and promotional genres (Leech 1966) entering marketised public services texts. This can take the form of synthetic expressions of familiarity (Fairclough 1992), rendered, for instance, through use of the personal pronouns we and you (and their associated forms). Leech (1966: 34) describes how the high frequency of such forms can indicate 'direct address advertising', in which 'both first and second persons are primary participants'. Leech contrasts this to 'indirect address advertising', in which 'the advertising message reaches the consumer through the mouths of secondary participants'. Increased use of both first- and second-person pronouns and other forms of direct address has been observed both in marketised texts pertaining to public services generally (Mautner 2010), as well as healthcare specifically (Brookes and Harvey 2016). The textual collapsing of power asymmetries between the 'providers' of public services and those with whom they engage is also realised through the use of low modality, particularly in relation to statements of obligation (Fairclough 1995a), with those engaging with public services being encouraged, rather than told, what to do. Here, the relationship between public services and their users is again reconfigured along the lines of a market economy.

While the marketisation of public services has attracted a fair amount of scholarly attention, particularly in the context of (higher) education marketisation, inquiry into marketisation of public health services is still under-researched. One example of a study of the discursive realisation of healthcare marketisation is that carried out by Brookes and Harvey (2016), who analysed multimodal marketizing 
discourses in the website of a single NHS CCGs. Studies have also been carried out on the broader, promotional discourses used in the commercial domain in relation to health-related products and services, providing insights into the discursive practices of the market economy - practices that the public sector may then in turn try to emulate as part of the broader process of marketisation. Examples of such studies include Arribas-Ayllon at al.'s (2011) study of direct-to-consumer genetic testing and Brookes and Harvey's (2015) study of commercialising discourses in a diabetes public health campaign.

The present study aims to contribute to the developing body of research on healthcare marketisation by examining how CCGs represent themselves and their actions in the contexts of their websites, with a view to understanding whether and how such representations contribute to the process of healthcare marketisation. This study builds in particular on the aforementioned qualitative study by Brookes and Harvey (2016), by examining the websites of not just a single CCG but all CCGs, with the help of a corpus-based approach to Critical Discourse Studies (CDS). This approach is introduced in the next section.

\section{Methodology}

As noted, in this study we adopt a corpus-based approach to CDS, combining the critical perspective and relevant concepts of CDS with the power and scalability of corpus linguistics methods. CDS is a type of discourse analytical research that primarily studies the way social power abuse, dominance, and inequality are enacted, reproduced, and resisted by text and talk in the social and political context' (van Dijk 2015: 466; see also Fairclough 1995b). The synthesis of corpus linguistics and CDS can be mutually enforcing, with each able to parry some of the limitations associated with the other (Brookes and McEnery 2020; Mautner 2010). Because CDS tends to be qualitative and interdisciplinary, its analyses usually focus on just a few texts. However, with corpus assistance, CDS can deal more effectively with larger and more representative datasets comprising thousands of texts and millions of words. In this study, corpus methods allow us to analyse the websites of all active 187 CCGs.

A further advantage of introducing corpus methods to CDS is that it can help critical scholars to increase the objectivity of their analyses, as it affords more predictable analytical techniques and advocates a spirit of methodological transparency underpinned by two guiding principles (McEnery and Hardie 2012). The first is that all available data is gathered for analysis (i.e. texts are not excluded on the grounds that they contradict a pre-existing argument or theory). The second is the 'principle of total accountability' (Leech 1992: 112), which postulates that all 
data gathered must be accounted for. However, corpus assistance does not grant complete objectivity, as human analysts are still required to make a series of procedural decisions respecting the use of corpus tools, such as selecting statistics and determining parameters and cut-offs, and are then required to interpret the analytical output.

Just as corpus methods can benefit CDS, so too can theories and concepts developed within CDS enrich corpus analyses, particularly at their more qualitative and interpretive stages. In this study, we draw upon insights from CDS research into advertising and marketisation in our interpretation of the transitivity choices evident in our corpus. Moreover, our analysis stands to benefit from CDS's commitment to analysing texts' social contexts. We also draw upon our understandings of the real-world social, political and healthcare landscapes in which the websites in our data were designed and are used.

\subsection{Corpus}

The data analysed in this paper is a specialised corpus comprising the text contained in the websites of all active CCGs (as of 2020). First, we consulted the list of all active CCGs provided by NHS England (https://www.england.nhs.uk/ccg-details/). This gave us a list of $187 \mathrm{CCG}$ websites. ${ }^{1}$ We then used an online sitemap generator to obtain a list of all URLs associated with each CCG homepage. Using the BootCaT tool, we downloaded all the text contained on each CCG website. This resulted in a corpus containing 187 text files - one per CCG - amounting to a total of 10,916,972 words. For the purpose of our analysis, each website is regarded as a 'text', although we do of course acknowledge that readers do not necessarily engage with websites as linearly as many other types of text; instead, they more likely navigate back and forth between pages according to their specific needs and interests.

\subsection{Analytical approach}

Our analysis of the CCGs' self-representation takes as its starting point the texts' transitivity choices, including choice of verbs, as well as participants and circumstances. Transitivity refers to the representation of what participants are depicted as doing, including who does what to whom, and how (Halliday 1985). Transitivity choices play a key role in the representation of social actors, whereby the

1 Note that we qualify this with the word 'active' because the website actually lists 188 CCGs. However, Derby and Derbyshire CCG is permanently closed, despite still being listed on the website. 
processes, participants and circumstances involved can implicitly promote (or background) certain discourses and ideologies. Halliday and Matthiessen (2004) distinguish six process types: material, mental, behavioural, verbal, relational and existential (introduced later). Since the possible affects and (potential) motivations of transitivity choices can only be fully apprehended through analysis of those choices in context, rather than simply cataloguing and quantifying the transitivity choices evident in a text or collection of texts, discourse analysts usually go beyond analysis of grammar alone by combining consideration of transitivity choices with analysis of the specific meanings or connotations of lexical choices in context, as is our approach here.

In practical terms, our approach is based on collocation, which can be understood as the phenomenon whereby words, by co-occurring more frequently than would be expected by chance, become bearers of situated meaning. Analysis of collocational patterns can help to reveal the semantic preferences of words, thereby enriching our understanding of the meanings words take on in particular contexts. The first step in our procedure was to use Wordsmith Tools (version 8; Scott 2020) to identify the word that the CCGs collectively used most frequently to lexicalise themselves in their websites. This was revealed to be the first-person plural pronoun, we $(n=69,831)$. A full analysis of transitivity, in the Hallidayan tradition, would explore the processes of which social actors are not only the subject but also the object. However, in our analysis we focus just on the processes which the CCGs construe themselves as carrying out. For this reason, we focus just on the subjective case we, rather than its objective equivalent, us $(n=17,861)$. We should note that $u s$, which tends to take on the object position, was much less frequent than we, which tends to take on the subject position, indicating that the CCGs were more likely to present themselves as doers of actions rather than as having actions performed on them. ${ }^{2}$

We then obtained a list of all right-sided collocates of we, occurring in the five words following the node (otherwise expressed as R1-R5) at least five times across the corpus. We ranked the resulting collocates using the cubed version of the Mutual Information statistic $\left(\mathrm{MI}^{3}\right)$. With traditional MI, collocation strength is determined through a comparison of the actual frequency of collocational pairings against their 'expected' frequency, given the frequency of each word relative to the overall size of the corpus. The difference between the actual and expected frequencies of collocation is then converted into an MI score, with stronger collocational pairings assigned higher scores. We selected the cubed version of MI because, in contrast to the traditional form which tends to emphasize exclusive and low-frequency word combinations, $\mathrm{MI}^{3}$ favours higher frequency pairings which tend to be more established in the discourse.

2 Of course, an exception to this is passive constructions. However, analysing a random sample of 500 uses of $u$ in the corpus, we found that $u s$ was used in passive voice in just $8 \%$ of cases. 
To focus on transitivity choices, we distilled our list of collocates so that it only contained verbs (including lexical and (modal) auxiliary verbs). To ensure that the collocates included did indeed function as verbs in at least half of their uses, we analysed a random sample of 100 uses of each collocate. ${ }^{3}$ In this analysis, we focus on the top thirty collocates, ranked by $\mathrm{MI}^{3}$. This cut-off seemed to provide a good balance between giving good coverage of processes for our analysis and not giving too many collocates to analyse at the same time (adding another ten collocates did not reveal any patterns that were substantially different from those already represented by the top thirty).

The next step in our procedure was more qualitative and involved analysing the collocates in Table 1 (next section) in their original contexts of use through concordance. Concordancing is essentially a way of viewing corpus data that allows the analyst to study every occurrence of a user-determined word or phrase (including collocational pairings) in the corpus within its wider contexts of use. With the searchword running down the centre of the screen and a few words of context displayed to the left and right, the concordance output provides a way for the analysts to examine patterns of use that might be less obvious during linear, left-to-right readings of the texts in the corpus. Based on analysis of a random sample of 100 uses of each collocate, we set out to identify patterns in the types of processes that the CCGs performed, as well as in the ways that they represented these, including in terms of participants and circumstances. Here we drew upon concepts from Systemic Functional Linguistics (SFL), as well as insights from existing research on advertising and critical literature on marketisation. To ascertain patterns pertaining to the representation of participants and circumstances of these processes, we also drew, where beneficial, on information about the other noun, adjective and adverbial collocates of the processes represented in the websites. In this sense, transitivity provides the starting point for our analysis but our analytical gaze is not restricted to transitivity choices alone in considering how the CCGs represent themselves and their actions. Both authors coded the samples independently for representational patterns before comparing findings and agreeing on shared interpretations.

\section{Findings}

As noted in the previous section, we began our analysis by generating a list of rightsided collocates (R1-R5) for the pronoun we. We then analysed these words in context and filtered the list, keeping only the verb collocates. The top thirty resultant verb collocates, ranked by $\mathrm{MI}^{3}$ are displayed in Table 1.

3 Note that we excluded verbs that tended to occur (in at least $50 \%$ of cases) in privacy and cookie policy statements. 
Table 1: Top thirty verb collocates of we (R1-R5), ranked by MI. ${ }^{3}$

\begin{tabular}{llrr}
\hline Rank & Word & Frequency & MI $^{3}$ \\
\hline 1 & have & 10,052 & 31.35 \\
2 & are & 11,681 & 31.28 \\
3 & want & 3,325 & 29.60 \\
4 & will & 6,477 & 29.32 \\
5 & do & 3,378 & 28.34 \\
6 & can & 4,441 & 27.73 \\
7 & need & 2,516 & 26.73 \\
8 & ensure & 1,952 & 26.63 \\
9 & make & 2,346 & 26.63 \\
10 & know & 1,681 & 26.51 \\
11 & would & 1,907 & 26.49 \\
12 & commission & 1,132 & 26.18 \\
13 & work & 2,109 & 26.09 \\
14 & hope & 682 & 25.45 \\
15 & committed & 909 & 25.43 \\
16 & be & 2,564 & 25.10 \\
17 & hold & 685 & 24.92 \\
18 & recommend & 600 & 24.91 \\
19 & advise & 699 & 24.90 \\
20 & hear & 659 & 24.39 \\
21 & working & 1,174 & 24.10 \\
22 & did & 556 & 23.91 \\
23 & understand & 668 & 23.58 \\
24 & continue & 754 & 23.46 \\
25 & recognise & 445 & 23.43 \\
26 & believe & 409 & 23.39 \\
27 & provide & 905 & 23.25 \\
28 & encourage & 496 & 22.95 \\
29 & look & 623 & 22.90 \\
30 & asking & 425 & 22.87 \\
\hline & & &
\end{tabular}

In what follows, we examine random samples of 100 uses of each of these collocates in terms of how they contribute to: (i) the representation of activities; and (ii) the attribution of values to the CCGs.

\subsection{Representing activities}

Our analysis begins by considering the ways in which the CCGs represent their activities. We observe that when they discuss their work, CCGs place particular focus on accomplished or continuous actions, with discussion of prospective work 
being less foregrounded, pointing to the fact that the CCGs' activities tend to be framed in ways that highlights their agency and effectiveness. We observed this particularly through the functional properties of certain collocates, verb aspect and modality. An example of this is the collocate which received the highest $\mathrm{MI}^{3}$ score; have. Have occurs as a right-sided collocate of we 10,052 times, mostly in the R1 position ( $n=7,957)$, that is, directly following the node to form the bigram 'we have'. Analysis of a random sample of 100 uses showed that, in 74\% of cases, have functions as an auxiliary to verbs in the perfect aspect (i.e. 'we have + past particle'), where the main verb represents a material process (Halliday 1985), as in the extract below (Note that all examples given henceforth were chosen as they were judged to be representative of the particular patterns of representation being discussed).

1. We have published information about the work that we have undertaken in meeting our public sector equality duties.

(Airedale)

This focus on material process arguably renders the work of the CCGs as more tangible. Meanwhile, the CCGs' use of perfect aspect in describing such process allows them to emphasise its completion and recency, foregrounding their productivity and representing the CCGs as goal-orientated and performance-driven.

A similar focus on agency is visible in auxiliary uses of the collocate are, ranked second in Table 1. Although it received a slightly lower $\mathrm{MI}^{3}$ score than have, it is worth noting that are is actually the most frequent right-sided collocate of we in the corpus ( $n=11,681$ ). In $47 \%$ of cases, are functions as an auxiliary verb in progressive aspect constructions (i.e. 'we are + present particle'). Again, the main verb in such instances tends to denote material processes, as in the extract below.

2. We are working hard with our partners on a 'pre-consultation business case' for changing the way health services...

(Ashford)

The progressive aspect of the verbs observed in such cases foregrounds the continuing nature of the described actions and their associated achievements. The impression that is created as a consequence is thus one of the CCGs as continually working to provide a consistently positive standard of service. A similar emphasis on the ongoing nature of actions performed by the CCGs can also be observed in the present tense uses of other verbs in Table 1, such as work and provide, as well as in uses of continue, as in the example below. 
3. This award ensures that as an organisation we continue to put young people at the heart of everything we do.

(Nene)

Leech (1966) described how the use of present tense forms in advertising can invoke the 'unrestricted present'. According to him, 'the unrestricted present, the most important use of this verb form, refers to a time period which includes the present moment, and also stretches indefinitely into the past and future, unless limitation is implied by other forms' (p. 123). In contrast to the 'instantaneous present', which excludes past and future time, the use of the unrestricted present is motivated by the desire of the text producer to 'make [their] claims as absolute as possible', whereby the 'virtues' of the product or service being described are applied 'for all time, like the laws of nature' (p. 123). Thus, we would argue that the CCGs' use of present tense can help to present their positively loaded actions and their associated values as continuing and enduring, rather than being applied to a particular point in time.

We have also observed a preference for material processes, which helps to lexicalise the work of the CCGs as more tangible. As well as reporting on completed and ongoing action, the CCGs also described desirable actions that they are committed to achieving in the future. Two collocates which provide a particularly interesting insight into how future actions are framed are the modal verb collocates will and can (ranked fourth and sixth in Table 1, respectively). Through the collocate can, the CCGs express possibility and describe their capabilities. Analysing 100 uses of the bigram 'we can' ( $n=4,005$ ), we note that the actions that the CCGs describe themselves as being able to carry out tend to orient around making improvements to service standards and collaborating with others, as in the extract below.

4. We can also work with the emergency department at Barnsley Hospital and Yorkshire Ambulance Service.

(Barnsley)

Meanwhile, through the high modality will, the CCGs tend to express commitment. Again, an analysis of 100 uses of this collocational pairing revealed this commitment being expressed mainly in relation to the 'quality' and 'value' of services - illdefined but positively loaded attributes which are implied to be high.

5. We will target our resources in the most effective way to ensure we offer value for money in the services we provide.

(Liverpool)

Both can and will serve as means for expressing dynamic modality. Can denotes the subject's ability to act while will denotes the subject's commitment to act. Leech (1966: 125) describes how, in the context of advertising texts, the verbs will and can 
respectively convey 'promise' and 'opportunity'. In this case, the CCGs tend to use can to foreground 'opportunities' to collaborate and work with others and to instigate improvements to their services, and will to 'promise' to instigate those improvements, or at least to uphold already high standards.

A collocate which performs a similar function to will is want. Following Halliday (1985), want can be designated as a mental, and specifically desirative, process. The effect of its use is that it construes intended actions as desirable on the part of the CCGs. In this case, the actions that the CCGs most frequently present themselves as want[ing] to do are, again, centred around ensuring that service standards (including 'value') remain high and are improving. As part of these processes, CCGs construe themselves as want[ing] to hear patients' views.

6. We want to ensure that we are making the best use of funding available to stroke patients.

(Durham)

7. We really want to hear your views and gather your ideas before making any decisions.

(Mid Essex)

Where can expresses opportunity or ability and will a promise or commitment, want can be said to express desire. Thus, as well as being committed to carrying out actions oriented towards positively loaded values such as upholding and improving service standards, collaboration and receiving patient feedback, the function of want is that it allows the CCGs to frame these actions as the result of their own self-determination and to align themselves with the positive values they signify.

Yet, the CCGs did construct certain actions as being the outcome of necessity, specifically through the collocate need. Analysing a sample of 100 uses, we found that in $87 \%$ of cases need was used in the expression of commitments to improve service standards and patients' experience, as the examples below show.

8. We need to improve the quality of care and patient experience.

(Barking)

9. We need to change the way we deliver planned care in Croydon to improve the care patients receive...

(Croydon)

Although these actions are portrayed as necessary, it is telling that in the sample analysed the need to improve standards was never attributed to anything other than the CCGs' (implied) desire for improvement (note that this pattern could also 
be observed in uses of the collocates do (i.e. 'we can do better') and make (i.e. 'we can make improvements')). In other words, the need to improve was never framed as the outcome of, for example, a report or instruction from another authority or care standards regulator, or even the outcome of patient feedback. Although in reality such factors do shape and drive the CCGs' pursuit of standard improvement, their obscuration from these contexts helps, we argue, to preserve the CCGs' status as active, self-deterministic and responsive, having an almost innate understanding of patients' needs.

The analysis so far has involved looking mostly at the patterns around grammatical or functional collocates, such as auxiliary and modal verbs. However, Table 1 also features collocates that are used to lexicalise the work of the CCGs more directly. One such verb is provide, which denotes a material process. In $45 \%$ of cases, goal of this process is service(s), while $27 \%$ of the time the goal is care.

10. We provide a highly responsive service that delivers care as close to home as possible.

(Airedale)

11. We all strive to provide the best possible care for our patients.

(Redditch)

As these examples demonstrate, these nouns are frequently pre-modified by positively loaded adjectives, in these cases highly responsive (10) and best possible (11). The use of such promotional rhetoric, but particularly superlative and comparative forms like best, enables the discursive expression of competitiveness and self-and-other differentiation among the healthcare providers (Leech 1966: 153), and thus highlights further the websites' commercial function and marketised nature.

Another collocate that describes the work of the CCGs is commission. The goal of this material process is almost always service(s) (92\% of cases). The use of the verb commission is not surprising, as it reflects the name and primary function of the CCGs, so we will not spend too much time discussing it here, except to note that its use renders the CCGs not as direct providers of healthcare services per se, but rather as facilitators of those services. We also note that the use of this term is seldom accompanied by an explanation of what commissioning of such services actually entails (found in just $4 \%$ of cases analysed).

Another main verb collocate used to lexicalise the work of the CCGs is help. Again, denoting a material process, this verb conveys the benevolence of the CCGs, as they are represented as assisting existing or prospective patients - lexicalised variously as people (30\% of cases), you (26\%), patients $(20 \%)$ and the public $(4 \%)$ - with their 
health-related concerns. As the extracts below demonstrate, these concerns are consistently framed as belonging to, and resting primarily with, patients.

12. We aim to: help people to look after themselves better.

(Croydon)

13. ...we can help empower patients into making the right choices...

(Baxley)

Such discourses can be linked to the neoliberal principle of individual responsibility, whereby the responsibility for looking after one's health is placed primarily on individual patients themselves, rather than the state or healthcare providers.

The responsibilisation of patients into self-care is evident in some uses of the collocate do, whose most frequent usage is in the communication of generalised health information, with the referent of we encompassing not only the CCG but also website users. This general reference is enabled by the inclusion of the pronoun qualifier all, as in the examples below.

14. We could all do with being a bit more active so try fitting exercise into your daily routine.

(Havering)

15. We can all do our bit to prevent heart disease.

(Lincolnshire West)

Of importance here is also the fact that the public health information is frequently framed through low deontic modality, whereby website users are positioned as agentive decision makers with regard to their health behaviours. On one hand, such strategies could be interpreted as being motivated by a concern for public health - an attempt by the CCGs to present their advice in a more appealing, indeed empowering, way to the public. Yet on the other hand, such forms of address also recall Fairclough's (2000) observation that marketised texts feature low levels of modality in order to maintain the appearance of an equal and intimate relationship between text creators and their audiences.

In this context of personal healthcare responsibility, the CCGs construe themselves as fulfilling a more facilitative and even administrative function, as is evidenced by uses of the collocates hold and spend, which respectively tend to be used to denote the holding of events and meetings (79\%) and to describe how money is spent responsibly or 'wisely' (94\%). The precise nature of these funding 
decisions, and the ways in which they may be considered responsible or wise, are not elaborated.

16. Every year we also hold an Annual General Meeting which is open to the public.

(Corby)

17. Our aim is to ensure the highest quality of care is delivered by the organisations best qualified to do so for the diverse needs of our patients, carers and the public, and at the best value for money so that we spend public money wisely.

(Central London)

Both hold and spend, then, while denoting material processes, are utilised in ways that help the CCGs to demonstrate accountability.

The theme of accountability also emerges in collocates which feature in requests for patient feedback, rendering CCGs more 'patient-centred' in approach (Baker et al. 2019). An important collocate in this regard is hear, a verb denoting a mental, and specifically perceptive process (Halliday 1985), used almost exclusively (99\% of cases) in attempts to elicit feedback from the patients and the public ( $98 \%$ of cases), and general practitioners (GPs) or other CCGs (2\%). Hearing from patients is constructed as something that the CCGs '(would) want' ( $40 \%$ of cases), 'would like' (23\%), 'are keen' on (11\%), 'would love' (7\%), 'need' (2\%) and are 'interested in' (1\%). As such, receiving feedback is constructed as something that the CCGs want and actively pursue, as opposed to it being a necessity or legal requirement (as is the case in reality).

18. We want to hear what you think of the services that are provided in this area.

(East North Hertfordshire)

19. We'd love to hear feedback about your experiences - both good and bad...

(Swale)

20. We are keen to hear from as many patients as possible.

(Luton)

There are other examples of verbs that point to the elicitation of such patient feedback, asking - and more specifically are asking (used in relation to the elicitation of feedback in $74 \%$ of cases) and encourage (used to elicit feedback in $28 \%$ of cases). The former presents the CCGs as continuously seeking feedback and the latter as doing so in more mitigated ways. 
While not always more polite than direct forms, this type of more indirect requests can demonstrate the interlocutor's orientation towards the mitigation of imposition of these requests. This can be likened, in turn, to the types of decreased expressions of obligation that have been observed by Fairclough (2000) in the contexts of marketised, neoliberal discourses of individualism, self-determination and choice.

Tied to the theme of accountability, and more specifically patient feedback, is the collocate did, which, in $60 \%$ of cases, features as part of the slogan, 'you said, we did'.

21. This 'you said, we did' approach to engagement and public interaction is embedded throughout Swindon CCG...

(Swindon)

This slogan denotes an initiative in which the CCGs publish reports demonstrating the ways in which they have implemented the insights gained from patient feedback in a bid to improve their services. Grammatically, the verbal process (i.e. 'said') carried out by the patient (i.e. 'you') has a causative effect, as it is implied to have stimulated the material process carried out by the CCGs (i.e. 'we did'), which is then framed as leading to service improvements. As well as constituting a form of marketing rhetoric then, this catchy slogan and the initiative and the practices it denotes also provide a glimpse into the bureaucratisation of the discourse in these websites.

The final collocates we consider in this section are the related verbs work and working. An analysis of 100 uses of each collocate revealed that both tend to be used, in approximately three quarters of cases (75\% for work, 77\% for working), to represent collaborations between CCGs and other organisations including other CCGs, the government, councils, the NHS and charities. The object of this work can be specified but can also be elided, as the examples below demonstrate.

22. We are working with the charity to develop top 10 tips for all Practices in Greater Nottingham...

(Nottingham West)

23. We work closely with other CCGs in West Yorkshire and Harrogate, as well as Bradford Council, NHS England and the public.

(Bradford)

This focus on the collaborative nature of the work carried out by the CCGs is further transmitted by the adverbial modifiers of both verbs, which include adverbs such as closely (used in relation to work in $22 \%$ of cases and working in $15 \%$ ), together (work: 20\%, working: 16\%) and collaboratively (work: 4\%, working: 8\%). In this sense, collaboration can be viewed as an important value for the CCGs and a key aspect of their organisational identity or online brand creation. 


\subsection{Attributing values}

We now move on to consider the values that the CCGs attribute to themselves. The analysis in the previous section alluded to some of the values with which the CCGs aligned themselves through the representation of their activities, including accountability, collaboration and patient-centredness, amongst others. While this alignment tended to be implicit, other collocates in Table 1 were deployed by the CCGs to attribute values to themselves in a more explicit way.

One such collocate is are (ranked 2nd). While this term tends to perform an auxiliary function, we can also see it functioning as a main verb, specifically a copula, linking the sentence subject (i.e. we) to its complement - typically, the specific qualities and values that the CCGs ascribe to themselves. In Hallidayan (1985) terms, are is used in this sense to depict existential processes, that is, the process of being. In analysing 100 uses of the bigram 'we are', which constitutes $10,618(91 \%)$ of the co-occurrences of we and are, we find that $27 \%$ are straightforward descriptions (e.g. 'we are a clinical commissioning group'). However, the remaining cases consist of, amongst other things, the self-attribution of positively loaded values such as being 'committed' (32\%), 'responsible' (15\%), 'passionate' (13\%) and 'ambitious' (10\%). A representative example of how such attributions manifest in the texts is given below.

24. We are an ambitious and forward thinking organisation.

(Bury)

The copular use of another collocate in Table 1, be, conveys qualities that the CCGs strive for. These are similarly positively loaded as the examples below suggest.

25. We aim to be an inclusive organisation firmly placing families at the heart of commissioning...

(Wiltshire)

26. We will be open, honest and transparent about the decisions we make...

(South Lincolnshire)

In inspecting the collocates following the bigram 'we are' (R1-R5), we find that the top three emotional states that the CCGs attribute to themselves include being delighted $(n=442)$, pleased $(n=353)$ and proud $(n=181)$. References to such positive emotional states typically accompany the discussion of recent and newsworthy events, including the provision of new services, openings, securing contracts and winning awards. 
27. We are delighted that we are now able to provide our support and counselling service to young people in Sefton...

(South Sefton)

The communication of such newsworthy events allows the CCGs to express their stance and also to present themselves in a positive light. Such passages thus contribute towards a process of (online) impression management (Rosenberg and Egbert 2011).

In our analysis of are, we noted how the CCGs could attribute certain positive emotive states to themselves. Other collocates in Table 1 are used to represent mental processes more directly. Two such collocates are recognise and believe, ranked 25 and 26th in Table 1 , which respectively denote perceptive and cognitive processes (Halliday 1985). Analysing 100 uses of recognise, we found some of the values that the CCGs mostly construed themselves as recognising included engaging the public (e.g. through feedback and consultation on decision making $(32 \%))$ and the need for bespoke care (28\%).

28. We recognise the importance of local engagement and decision making...

(Hounslow)

Meanwhile, the things that the CCGs believe (in) include collaboration (21\%), public engagement (11\%) and that their actions and decisions will improve service standards (10\%).

29. We believe in the power of partnership working.

(Ashford)

As in some uses of believe noted above, another mental process collocate, hope (ranked 14th in Table 1), tentatively expresses expectations that changes being implemented will be received well by patients and improve their experiences of services. It thus also performs a legitimation function, enabling the CCGs to further display accountability for their decisions:

30. We hope that the new service will make the patient experience smoother.

(Wirral)

31. We hope people will prefer to use this method [of ordering prescription], as it puts more control in the hands of patients...

(Buckinghamshire)

A similarly argumentative function, tied also to epistemic modality, can be found in the use of other verbs depicting the cognitive process, know and understand, as well as in some uses of the perceptive recognise (Halliday 1985). Each of the three 
verbs could be used to acknowledge particular negative situation and state, as the extracts below demonstrate.

32. We know we face a huge financial challenge but the future for healthcare in Barnet is entering a new and exciting phase...

(Barnet)

33. We understand your concerns but can assure you that all of your records and patient information will be transferred securely to your new GP practice...

(South Kent Coast)

34. We recognise additional resources are needed to deliver these improvements and a key part of the plan includes substantial additional investment...

(Brighton)

As these examples show, the high epistemic modality verbs function as part of the rhetorical organization of a problem-solution structure. Specifically, the CCGs outline a specific, known problem that they face and which is likely to frustrate patients (i.e. the given) and follow this up with a solution (i.e. the new) which is more positively evaluated, for example in (32) as a 'new and exciting phase'. Through this persuasive device, the CCGs are able to represent themselves as empathic and patient-centred, as they are cognisant of patients' concerns, but at the same time as agentive and proactive in their response. This rhetorical device can be interpreted as a further means of impression management, whereby the CCGs recontextualise a negative state of affairs into one where their empathy and responsiveness are foregrounded.

\section{Discussion}

The analysis of the CCG websites reported in this paper has focused on the use of transitivity in the ways that the CCGs represent their actions and values. The first part of the analysis, which addressed the representation of actions, noted the tendency for the websites to conceptualise their work in terms of material processes. These processes comprise a mixture of completed, ongoing and future actions, allowing the CCGs to construe themselves, respectively, as effective, as providing an ongoing and continuously positive standard of service, and as goaloriented and target-driven. In this representation, we observed the presence of discourses traditionally associated with the commercial sphere. When describing 
their work, the CCGs are observed to place emphasis on accountability, being performance-driven and competitive, all of these being tied closely to the market economy. The focus on accountability and goal-orientation is visible, for example, in the auxiliary employment of have and are (e.g. 'we have published information' or 'we are working hard with our partners'), where the use of the verbs is tied closely to the expression of the completion or continuation of a performance of a task. Using verbs such as will, can, want and need, the CCGs describe themselves as willing, wanting or having to commit to positively loaded future actions, including, amongst others, upholding and improving the value and quality of the services they commission.

What is described by Mautner (2010) as the language of 'deliverology' is visible also in the lexicalisation of work carried out by the CCGs. In addition to their general tendency to employ verbs belonging to the category of 'material' processes described by Halliday (1985), this is particularly tangible in the verbs deliver, commission and provide, which often take the object of quantifiable or qualifiable service(s) or care. This directly maps onto the observations made by Mautner (2010), Furedi (2011), and Morrish and Sauntson (2013), who note that public services are increasingly being reconfigured into commodities. In our data, through the discursive commodification and finalisation of the services rendered by the CCGs, the work carried out by them becomes easily quantifiable and consequently accounted for. It also acquires a firm financial basis. Moreover, the CCGs - through the employment of superlative and comparative forms when qualifying such services(s) or care - draw upon marketised discourses of competitiveness and self-and-other differentiation, both linked closely to advertising rhetoric (Leech 1966) and the broader discourses associated with the market economy.

Despite their preference for representing their activities as material processes, thus granting them a degree of seeming tangibility, we also note that the precise details pertaining to healthcare provision - in other words, what commission[ing] is and how the CCGs help patients, provide care, and uphold and improve standards rarely go beyond the rather vague, if at times positively loaded, descriptions given. Instead, the CCGs were more explicit regarding the administrative and bureaucratic functions, for example holding meetings and events, while the business of ensuring patient health exhibited a decidedly neoliberal tone, with patients responsibilised for their own wellbeing. This can, moreover, be linked to the process of marketisation, since members of the public generally, and website users specifically, are positioned as consumers of healthcare, responsible for looking after their health and for selecting the 'best' healthcare provider - including CCGs - to enable them to do that. The role of the CCGs in this reconfigured relationship between provider and patient is thus one which involves facilitating - including planning, commissioning and allocating care, rather than providing it to patients directly. 
Marketising discourses, and particularly those which emphasised competitiveness and differentiation, were also visible in the description and self-ascription of the CCGs' attributes, values and cognitive states. Through their use of the copula are, for example, the CCGs not only engage in the process of self-attribution of positively evaluative qualities and values, but also produce what can be described as corporate boasts (Morrish and Sauntson 2013). This self-ascription of positive values and actions consequently allows the CCGs to produce self-promotional discourse and engage in the process of (online) impression management. Even when describing or acknowledging negative valance states, often drawing upon verbs such as know, understand and recognise, this acknowledgment forms part of a wider rhetorical structure, being framed along the lines of problem-solution structures. The discourse produced in such cases enables the CCGs to promote their solutions and to present themselves as responsive and proactive problem-solvers in a manner reminiscent of commercial, promotional genres.

Overall, then, our analysis has found substantial evidence of the integration of market economy rhetoric into the language of CCG websites. Leech (1966: 64) distinguishes between traditional consumer advertising, which promotes particular products and services, and 'prestige advertising', which promotes the commercial enterprise itself; '[w] hereas in consumer advertising a firm advertises what it makes, in prestige advertising it advertises itself.' In promoting the actions, achievements and values of the CCGs, they do not promote the quality or specific qualities of the healthcare services they commission but instead promote their role in upholding and improving the standards of those services.

Indeed, other, more specific aspects of the discourses identified by our analysis reflect some of the general features of prestige advertising noted by Leech; ' $[t]$ he tone is less urgent than in consumer advertising; imperatives are infrequent, and the more brazen forms of eulogy are absent' (p. 64). Further, '[i]n prestige advertising, self-eulogy is often hidden in board-room clichés which imply the dynamism, success, and health of the firm's activities' (Leech 1966: 65). The aim of such advertising, then, is not to directly or explicitly encourage the take-up of a particular product or service but, rather, is intended to craft a positive impression of the organisation amongst the public and to encourage alignment with it. For this reason, Leech describes prestige advertising as being 'on the borders of advertising and public relations', as it 'seeks not so much to promote sales, as to bring about an alignment of public opinion with commercial interests' (1966: 25). As noted at the beginning of this paper, the process of marketisation is not instant and, in the case of health(care), not particularly recent either, and Leech noted how prestige advertising was not the reserve of commercial enterprises but could also be initiated by Government departments and non-profit-making bodies. 


\section{Conclusion}

Our corpus-based analysis has demonstrated how CCGs' self-representations contribute to a process of NHS marketisation. We thus argue that these websites operate like commercial texts, and in particular forms of prestige advertising, designed with the aim of promoting the brands and activities of the CCGs rather than necessarily providing the type of health(care) information that would be useful to website users in making day-to-day health decisions. As well as being of - we would argue, questionable - practical value to members of the public, we can also consider the macro-level, societal implications of the CCGs' marketising discourses. The types of marketising discourses we have identified in this paper both legitimise, and are themselves legitimised by, the process of privatisation. However, this gives rise to a number of potential issues and questions, not least concerning the often uneasy, and potentially impossible, reconciliation of some of the values and beliefs of the commercial and public domains. The principle of equal access to consistent healthcare that is set out in the National Health Service Act $1946,{ }^{4}$ and which subsequently underpinned the establishment of the NHS in 1948, can be contrasted patently with the rhetoric of competitiveness, differentiation and individual health responsibility that is pervasive in the representations of the activities and values of the CCGs found in their websites.

In defence of the CCGs, we might argue that the marketising discourses we have identified in our analysis simply reflect the reality that these organisations are forced to operate within an increasingly commercial, privatised healthcare context, in which they must first compete with one another for everscarcer public healthcare funds and then demonstrate their ability to deliver value for those funds, including by differentiating themselves with other CCGs. In other words, it is not that the CCGs' discourses instigate healthcare marketisation but, rather, are most likely to reflect broader, longer-term social processes, the instigators of which are more powerful and likely less welldefined. This caveat notwithstanding, these processes have met with strong opposition from the general public (YouGov 2017) and professional bodies, including the British Medical Association (Meldrum 2010). In this context, we urge future research that monitors the development of this social and policy landscape in the future.

On a methodological note, the CCG websites analysed in this study have provided useful insights into some of the discourses surrounding contemporary

4 http://www.legislation.gov.uk/ukpga/Geo6/9-10/81/enacted. 
healthcare in the UK, discourses that have the power to shape social relations between patients and providers. The synthesis of corpus linguistics and CDS has enriched our account of these texts, enabling the combination of the granularity and context-sensitivity of CDS with the power and scalability of corpus methods. Our analysis has demonstrated how corpus-aided critical studies of vast datasets can benefit from drawing on the insights from previous studies to interpret the significance of frequent patterns or features. In our case, our interpretation of the CCGs' language use as belonging to marketising discourses was enriched, and to an extent enabled, by our recourse to insights gleaned from previous research of advertising and marketisation. By gathering all available texts, outlining clearly our data selection processes, and focusing on the most frequent patterns of representation, our critical account of these texts has been motivated by the principle of 'total accountability' espoused by Leech (1992), helping, we hope, to counter the criticism of analytical 'cherry-picking' often directed at (critical) discourse analysts.

Despite these merits, the corpus-based approach to CDS employed in this study is not without limitation. First, while corpus linguistics grants critical discourse analysts more objective methods based on more representative datasets and criteria, it is not possible for any research to be completely unbiased. Our interpretations of the patterns in our corpus were undoubtedly shaped by our own identities and cognitive biases, as well as our prior awareness of the marketizing process. It is possible that other analysis, perhaps less attuned to ongoing debates around healthcare privatisation, would not interpret the patterns we have reported as evidence of marketisation in the ways that we have. To an extent, this is true of all social research and, in relation to CDS it is something we are encouraged to acknowledge and be reflexive about, rather than view straightforwardly as a limitation of analysis. A second point to note here, and one which may be addressed more straightforwardly, is that our analysis has explored just one aspect of the CCGs' self-representation (mainly transitivity choices). There are doubtless other ways in which the CCGs represent themselves in their websites, and future research could take a broader approach to explore these. Similarly, CCGs also produce texts other than their websites, including patient leaflets or social media accounts. Such texts could provide further self-representations which, for this reason, are worthy of study. 


\section{References}

Arribas-Ayllon, Michael, Sarangi Srikant \& Angus Clarke. 2011. Promissory accounts of personalisation in the commercialisation of genomic knowledge. Communication \& Medicine 8(1). 53-66.

Baker, Paul, Gavin Brookes \& Craig Evans. 2019. The language of patient feedback: A corpus linguistic study of online health communication. London: Routledge.

Barnett, Ronald. 2000. Realizing the university in an age of supercomplexity. Buckingham: Society for Research into Higher Education and Open University Press.

Brookes, Gavin \& Kevin Harvey. 2015. Peddling a semiotics of fear: A critical examination of scare tactics and commercial strategies in public health promotion. Social Semiotics 25(1). 57-80.

Brookes, Gavin \& Kevin Harvey. 2016. Opening up the NHS to market: Using multimodal critical discourse analysis to examine the ongoing corporatisation of health care communication. Journal of Language and Politics 15(3). 288-302.

Brookes, Gavin \& Tony McEnery. 2020. Correlation, collocation and cohesion: A corpus based critical analysis of violent jihadist discourse. Discourse \& Society 31(4). 351-373.

Fairclough, Norman. 1992. Discourse and text: Linguistic and intertextual analysis within discourse analysis. Discourse \& Society 3(2). 193-217.

Fairclough, Norman. 1995a. Critical discourse analysis and the marketization of public discourse: The universities. Discourse \& Society 4(2). 133-168.

Fairclough, Norman. 1995b. Critical discourse analysis: The critical study of language. London: Longman.

Fairclough, Norman. 2000. Multiliteracies and language: Orders of discourse and intertextuality. In Bill Cope \& Mary Kalantzis (eds.), Multiliteracies: Literacy learning and the design of social futures, 162-181. London: Routledge.

Furedi, Frank. 2011. Introduction to the marketisation of higher education and the student as consumer. In Mike Molesworth, Richard Scullion \& Elizabeth Nixon (eds.), The marketisation of higher education and the students as consumer, 1-8. London: Routledge.

Halliday, Michael. 1985. An introduction to functional grammar. London: Edward Arnold.

Halliday, Michael \& Christian Matthiessen. 2004. An introduction to functional grammar. London: Hodder Arnold.

Krachler, Nick \& lan Greer. 2015. When does marketisation lead to privatisation? Profit making in English health services after the 2012 Health and Social Care Act. Social Science \& Medicine 124. 215-223.

Leech, Geoffrey. 1966. English in advertising: A linguistic study of advertising in Great Britain. London: Longman.

Leech, Geoffrey. 1992. Corpora and theories of linguistic performance. In Svartvik Jan (ed.), Directions in corpus linguistics: Proceedings of the Nobel Symposium 82, Stockholm, 4-8 August 1991, 105-22. Berlin: Mouton de Gruyter.

Mautner, Gerlinde. 2010. Language and the market society: Critical reflections on discourse and dominance. London: Routledge.

McEnery, Tony \& Andrew Hardie. 2012. Corpus linguistics: Method, theory and practice. Cambridge: Cambridge University Press.

Meldrum, Hamish. 2010. Stop this wasteful commercialisation of the NHS. British Medical Journal 340. 571-573. 
Morrish, Liz \& Helen Sauntson. 2013. 'Business-facing motors for economic development': An appraisal analysis of visions and values in the marketized UK University. Critical Discourse Studies 10(1). 61-80.

Ozga, Jenny. 1998. The entrepreneurial researcher: Re-formations of identity in the research marketplace. International Studies in Sociology of Education 8(2). 143-153.

Rosenberg, Jenny \& Nichole Egbert. 2011. Online impression management: Personality traits and concerns for secondary goals as predictors of self-presentation tactics on Facebook. Journal of Computer-Mediated Communication 17(1). 1-18.

Sarangi, Srikant \& Stef Slembrouck. 1996. Language, bureaucracy and social control. London: Longman.

Scott, Mike. 2020. WordSmith tools version 8. Stroud: Lexical Analysis Software.

van Dijk, Teun. 2015. Critical discourse analysis. In Deborah Tannen, Heidi E. Hamilton \& Deborah Schiffrin (eds.), The handbook of discourse analysis, 2nd edn. 466-485. Oxford: Wiley Blackwell.

YouGov. 2017. Nationalisation versus privatisation: The public view. https://yougov.co.uk/ topics/politics/articles-reports/2017/05/19/nationalisation-vsprivatisation-public-view (accessed 17 August 2019).

\section{Bionotes}

\section{Matgorzata Chatupnik}

School of English, University of Nottingham, Nottingham, UK malgorzata.chalupnik@nottingham.ac.uk

Matgorzata Chatupnik is Teaching Associate in Linguistics and Professional Communication working in the School of English at the University of Nottingham. She conducts research in the area of professional communication, focusing in particular on leadership and interpersonal aspects of talk at work. She has carried out research, training and consultancy work with a wide range of public, private and third sector organisations from across the UK.

\section{Gavin Brookes}

Linguistics and English Language, Lancaster University, Bailrigg, Lancaster, UK g.brookes@lancaster.ac.uk

Gavin Brookes is a Research Fellow in the Department of Linguistics and English Language at Lancaster University. His research utilises corpus linguistic and multimodal approaches to discourse analysis to examine communication in health(care) contexts. He is Associate Editor of the International Journal of Corpus Linguistics and Co-Editor of the Corpus and Discourse book series. 